\author{
Diego CARABIAs ${ }^{* * * * *}$ \\ Christian García
}

\section{Reflexiones sobre el concepto de maritorio y su relevancia para los estudios de Chiloé contemporáneo*}

Reflections on the concept of maritorium and its relevance for contemporary Chiloé studies

\section{Ricardo Álvarez ${ }^{* *}$ \\ FRANCISCO THER-Ríos ${ }^{\star * \star}$ JuAn Carlos SKewes ${ }^{* * * *}$ \\ CARLOS HIDALGO ${ }^{\star \star \star \star * \star}$}

Proyecto FONDECYT 1171827 "Coastal behaviors settings": por una Antropología de la Recomposición Territorial en el Archipiélago de Chiloé".

** Antropólogo. Investigador asociado a programa ATLAS, Universidad de Los Lagos, Osorno. Investigador asociado ARQMAR, Centre for Maritime Archaeology Research of the South Eastern Pacific. Muelle Barón S/N, Valparaiso. E-mail: taijataf@ gmail.com

*** Antropólogo. Dr. en Antropología. Director Programa ATLAS CEDER, Universidad de Los Lagos, Osorno. E-mail: fther@ulagos.cl

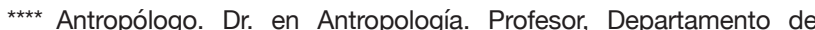
Antropología, Universidad Alberto Hurtado. E-mail: jskewes@ uahurtado.cl

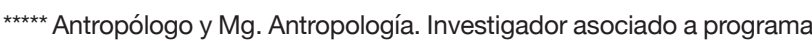
ATLAS, Universidad de Los Lagos, Osorno. E-mail: chidalgarrido@ gmail.com

\section{Resumen}

El concepto de maritorio, como imagen del 'territorio' pero desde y en el mar, se contextualiza en la denominada nisología o estudio de las islas. Desde su proposición, en las aulas de la escuela de arquitectura de la PUCV en la década de los '70, se ha expandido su uso hacia múltiples reflexiones y discursos, frecuentemente ligados a la complejidad archipelágica -geográfica y humana- que caracteriza a buena parte de nuestro país. En este artículo se discute la historia del concepto y los alcances que ha tenido para pensar en y desde esta insularidad respecto al modelo de desarrollo imperante y los modelos alternos, y cómo el propio término maritorio recupera su esencia original: ser una crítica constructiva respecto a esta controversia y no una frase que simplemente describe un paisaje.

Palabras clave: Maritorio, insularidad, archipiélago, Chiloé, modelo consuetudinario.

\footnotetext{
Abstract

The concept of maritorium, as an image of 'territory' from and on the sea, is contextualized in the so-called nissology or islands studies. Ever

Arqueólogo. ARQMAR, Centre for Maritime Archaeology Research of the South Eastern Pacific. Muelle Barón S/N, Valparaiso. E-mail: dcarabias@arqmar.org

Arquitecto. Secretario Delegación Chiloé, Colegio de Arquitectos de Chile. Castro. E-mail: christiangarciariffo@gmail.com
} 
since it was first proposed in the PUCV School of Architecture of the 70's, its use has spread towards multiple reflections and discourses, frequently related to the archipelagic complexity -geographical and human- that characterizes Chile. In this paper, we discuss the history of the concept and its capacity to foster reflections within and from this condition of insularity, in accordance to dominant as well as alternative modes of development. Within this framework, the concept goes back to its original essence: being a constructive critique and not just a term used to describe a landscape.

Key words: Maritorium, insularity, archipelago, Chiloé, customary model.

\section{Introducción}

El concepto de maritorio aborda dinámicas territoriales en contextos archipelágicos, de mar protegido o mar interior (v gr. IHO - International Hydrographic Organization), donde la presencia marítima se confunde con la terrestre de manera intersticial, y en la que la actividad humana demuestra un comportamiento transicional y no disruptivo, por lo que pareciera prescindir de las fronteras que convencionalmente se han impuesto al territorio en el continente. Esta situación es visible en el Archipiélago de Chiloé, y en referencia a ello se acuñó este concepto a inicios de los años setenta. No siempre la literatura es justa y pertinente con los orígenes y utilización del concepto de maritorio, ni con sus implicancias tanto para la comprensión teórica de los procesos socioculturales y socioambientales particulares, como para servir de contrapunto a las economías extractivistas promovidas. Es por ello que pretendemos contribuir con una reflexión del concepto.
Desde su aparición en la década de 1970, el maritorio casi siempre ha estado referido espacialmente al Mar Interior de Chiloé1, zona caracterizada por una insularidad poblada desde tiempos precolombinos en la que se gestó un fuerte mestizaje hispano-indígena, y un modo de vida particular y reconocible identitariamente -de carácter consuetudinario (Skewes et al. 2012a)- y que hoy reacciona de forma traumática ante el modelo de desarrollo hegemónico. ${ }^{2}$

El concepto se ha extendido hacia los canales australes de las Regiones de Aysén y Magallanes. En todos los casos se trata de un intrincado paisaje archipelágico, isleño y de canales, que posee dos fisonomías características: el Mar Interior de Chiloé, compuesto por islas habitadas casi en su totalidad en las que se observan múltiples expresiones productivas; y los Canales Australes, cuyas islas están escasamente habitadas y en las que imperan las inversiones privadas y la pesca artesanal extractiva.

En este mar interior de Chiloé ocurrió un tipo de poblamiento histórico que se expresa materialmente en una transicionalidad martierra, o tierra-mar, que instó a problematizar este escenario territorial particular, por sobre todo en un país que tiene una marcada noción de sí mismo altamente continentalizada. Lo interesante del caso es que esta transicionalidad

(4128'21.43"S/7256'16.67"O - 43³7'29.51"S/7353'25.96”O)

\footnotetext{
Desde un punto de vista ecológico, el archipiélago de Chiloé tiene las características de un ecotono, a saber, una zona de transición entre dos ecosistemas. Entre los ecotonos se destacan aquellos que se sitúan en la interfase tierra-agua y cuyo comportamiento es análogo al que, en el caso que nos ocupa, han desplegado a través de sus prácticas consuetudinarias los habitantes del Archipiélago de Chiloé (para una discusión del concepto de ecotono, ver Kolasa y Zalewski, 1995).
} 
aún hoy es apreciable desde diferentes escalas. La Figura 1 muestra cómo las formas terrestres que adquiere el paisaje insular se asocian al modelo consuetudinario chilote (Skewes et al. 2012a), y se transfieren al intermareal a través de la configuración de corrales de pesca (Álvarez 2016), estructuras destinadas a la captura de peces a partir del aprovechamiento de las mareas. No se trata de una imagen antojadiza. Por el contrario, evidencia un registro, una expresión material de una cultura insular que nunca dicotomizó entre tierra y mar. Por el contrario, su cotidianeidad, trabajo y festividad interactuaban constantemente en el mar, la tierra y el intermareal, como lo hacen las mareas.

El maritorio fue construyéndose a través de la navegación hacia los canales australes, adecuándose a las particularidades del territorio. Las embarcaciones fueron, a la vez, el hogar que se movilizaba ${ }^{3}$. Posibilitaban la navegación y dormir con seguridad. También eran el espacio de alimentación y vida cotidiana, donde se planificaban nuevos proyectos de vida. Este comportamiento sigue estando vigente, pero debilitado debido a una serie de normativas que han restringido la libertad de navegar y más bien la han transformado en un ejercicio funcional para las actividades productivas.

Esta forma de habitar y comprender el mundo comenzó a ser violentada cuando el Estado comenzó a incorporar económicamente estas zonas, promoviendo el despliegue de intereses comerciales, facilitando la implementación y expansión de un modelo de desarrollo esencialmente extractivista. Para ello se instauraron regulaciones que facilitaron este

Y ocasionalmente las viviendas se transformaban en naves que eran trasladadas desde una orilla a otra proceso. En lo fundamental, la intervención pública separó de forma tajante lo que antes era transicional, compartimentando los recursos para su explotación $n^{4}$. Cuando el efecto negativo sobre los recursos explotados se hizo patente, se agregaron nuevas regulaciones para controlar los modos de trabajar y habitar. Este fenómeno, siempre de tipo top down, provocó un efecto traumático sobre las comunidades insulares, problema que sigue vigente y que en lugar de solucionar el problema sólo lo ha agudizado (FSP 2016).

Figura 1. Costa sureste de isla Apiao, subgrupo archipielágico de Quinchao. El espacio terrestre (a) transita hacia el mar por medio de los corrales de pesca (b).

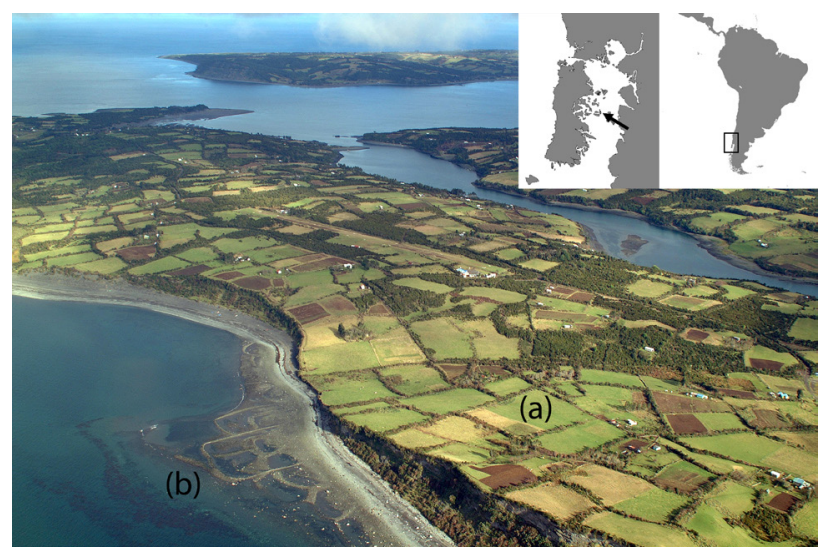

Fotografía: Drago Bartulín 2004

Una buena parte de la acción del Estado se ha concentrado, en el contexto de la modernización neoliberal de la economía en Chile, a individualizar los recursos a objeto de promover su privatización y extracción. El establecimiento de cuotas de pesca, la definición de áreas de manejo, el ordenamiento territorial, entre muchos otros instrumentos, dan cuenta de una cartografía política cuyo eje central es la demarcación territorial y que refleja lo que James C. Scott (1998) denomina la mirada del Estado. 
A propósito de ello, tal vez la discusión sobre este concepto sirva para repensar estos dos mundos: uno que portaba una cultura sobre el mar, tanto objeto como sujeto en su cosmovisión; y otro que sólo ve un objeto que debe ser utilizado para generar acumulación por desposesión. De hecho, el paisaje insular en el que nació el concepto de maritorio es de carácter dendricular (Skewes et al. 2012b). Esto es, sujeto a la adecuación de las poblaciones a las particularidades del entorno sin imponer una morfología en el habitar. Se observa cómo las labores productivas, los asentamientos y la comunicación entre los habitantes se hacen símiles al paisaje. Los nuevos escenarios productivos han roto esta lógica y los transforman radicalmente para imponer un arreglo favorable para la extracción de materias primas.

\section{Historia del concepto de maritorio}

La primera referencia al concepto surge en 1970, en los talleres de la PUCV ${ }^{5}$ (Escuela de Arquitectura PUCV 1971, Ivelic 2005), como parte del análisis que estaba desarrollando en el sur de Chile la Escuela de Arquitectura de la Universidad Católica de Valparaíso referente a los tipos de embarcaciones que existían en ese momento, y cómo eran utilizadas por los habitantes locales para generar nuevos asentamientos costeros. Lo que llamaba la atención a este equipo era que se denotaban dos ejercicios de poblamiento: uno basado en el modelo consuetudinario, en el que los habitantes eran capaces de portar sobre el agua su cultura recurriendo a los elementos que los rodeaban para establecer nuevos

Pontificia Universidad Católica de Valparaíso asentamientos (Figura 2); y otro, impuesto por el Estado, basado en la aproximación de artefactos e inversión pública con los que extraer recursos naturales, siempre sustentado en la conectividad vial para acercar lo capturado desde la periferia al centro, encausando una enorme cantidad de energía para transformar las especies hidrobiólogicas en recursos pesqueros, e imponer una forma de habitar planificada en gabinete.

Figura 2. Pequeño asentamiento costero en la costa interior de isla Asención, en Las Guaitecas. Gradualmente fue adquiriendo una toponimia, una biografía y un reconocimiento en la cartografía formal. Su nacimiento obedeció al transporte del modelo consuetudinario para fundar este lugar.

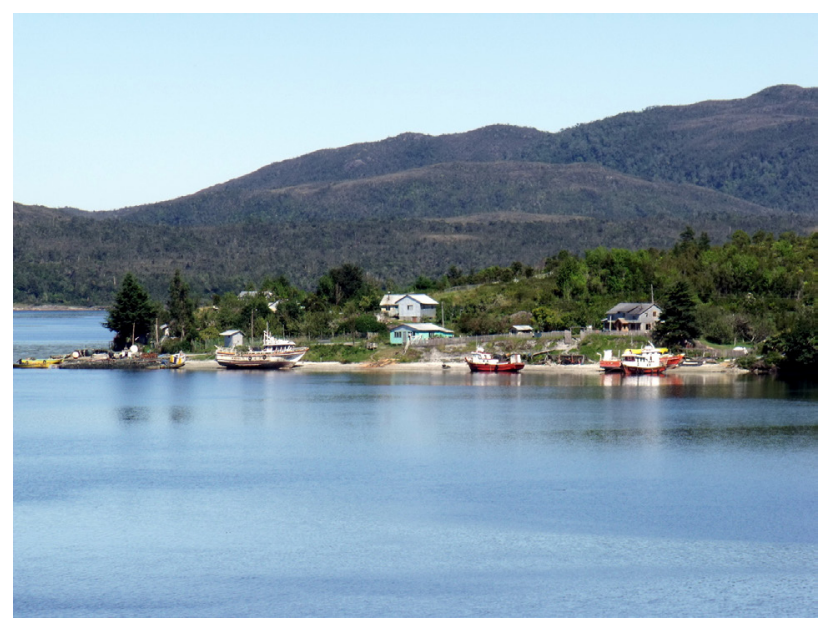

Fotografía: Repollal Alto, comuna de Las Guaitecas, Ricardo Álvarez 2010

Un aspecto relevante en este ejercicio es que los asentamientos históricos prescindían de artefactos para la construcción de caminos o de energía que no fuese la propia, la que sus animales pudiesen proveerles, o la que 
canalizarían a través de ingenios ${ }^{6}$. Si se requería de un puente, o una pasarela aérea, 0 un molino de agua para transformar los granos cosechados, era la población local la que recurría a su experiencia acumulada para resolver esta carencia. Esto contrasta con las iniciativas actuales que procuran arreglar lo rural para que parezca lo más urbano posible (y por tanto de fácil manipulación centralizada), y, cuando no, despoblar los campos (Guerra 2013).

El Archipiélago de Chiloé surgió entonces como referente inicial para formular el concepto de maritorio pensando en el mar transformado cotidianamente, y a través de distintas e históricas apropiaciones, en un mar territorializado o maritorio. Luego fue ampliada su cobertura geográfica hasta los extremos australes.

La palabra nace en Valparaíso a propósito de un estudio sobre la razón de ser de la localización de sus ciudades costeras. Tal como se fundaba en el territorio, surge el territorio como concepción de magnitud de mar. El Maritorio es un concepto de área geográfica que conjuga: la comunicabilidad, la riqueza, la adversidad y las energías. Conociendo estos cuatro aspectos es que se pueden determinar áreas armónicas. Para poblar hay que fundar en la complejidad del área -“Maritorio"- única manera de constituir ciudad (Ivelic 2005: 1-2).

La perspectiva que inspiraba a los arquitectos no era la de producir, sino la del habitar; tempranamente advirtieron la necesidad de adecuarse a las características de un determinado territorio más que en la compulsión por transformarlo, compulsión que asociaron a la miopía extractivista:

También llamados en esta zona artilugios, creaciones basadas en la creatividad local. Éstas podían ser inéditas, o hechas en referencia a artefactos observados en otro lugar y recreados en la insularidad
Fundar con un solo fin no es poblar (puede ser defender, explotar, etc.). Solo nos conduce a establecer factorías o campamentos (...) Nuestra hipótesis de trabajo no se funda en la productividad potencial de territorio, que no ha sido reconocida, sino en un intento de entregar los elementos de análisis a quienes les competa, en vista a refundar el uso e incorporación de un territorio al lenguaje regional y nacional” (Op.cit).

El maritorio reclamaba un cambio de racionalidad en la planificación estatal de los canales australes. Sobre todo, se trataba de re-mirar la forma en la que se fundaban nuevos espacios poblados más allá de intereses comerciales "sólo es posible fundar en una completitud aunando ocio y negocio. Fundar con un solo fin no es fundar" (Ivelic 2005: 37). Considerar bajo el prisma del maritorio incluso la acuicultura era imaginada de manera distinta "Los canales son los valles de la Patagonia, única superficie plana. En ellos hoy se empieza a cultivar el mar. La acuicultura, al igual que la agricultura, transforma al hombre nómade en sedentario, lo arraiga a la tierra-mar para fundarla y cuidarla. Fundar es conjugar el ocio y el negocio y amor por la morada y el terruño" (Ivelic 2005: 21).

Resultó visionario establecer este llamado de atención. Sus alcances incluían dimensiones tanto teóricas como prácticas. Se anticipaba, a su modo, a la crítica que se formularan en la antropología respecto a las visiones esencialistas de la cultura y de los territorios (ver, por ejemplo, la colección editada por Gupta y Ferguson [1997]), e invitaban a reconocer la fluidez de procesos que hoy conocemos como dinámicas socioambientales en interacción con las dinámicas socioculturales y productivas. En su dimensión práctica, la propuesta de los arquitectos de la Universidad de Valparaíso llamaba a promover los espacios territoriales colectivos y no los intereses comerciales de grupos particulares. Pero la propuesta no fue 
acogiday durante la década de los '80 conocimos los más extremos episodios extractivistas en el espacio marino-costero, generándose procesos migratorios imprevistos y muy significativos en lo cultural y en lo socioproductivo, y lesivos en cuanto a la calidad de vida y del medio ambiente. En los '90 y 2000 fuimos testigos de la masificación de la salmonicultura, y la expansión urbana más allá de los límites posibles e imaginables. Simultáneamente, y al regreso de la democracia en Chile, se potenció la privatización del mar para fines comerciales.

\section{El concepto de maritorio hoy en día}

Hoy en día el concepto ha continuado siendo utilizado bajo parámetros similares a los de su origen, como una suerte de transición entre dos cuerpos (terrestre y marítimo) que frecuentemente son tratados como dos unidades distintas "(...) hacer habitable el mar para romper conceptualmente el límite del mar con la tierra como obstáculo y, por el contrario, crear un ancho de fusión de agua y tierra" (Ivelic y Segura 2016: 88), pero también complejizándose como "(...) un lugar entre tierra y río, entre el Nervión y el Galindo, entre la ría y el mar, entre terreno de relleno y agua oscilante, entre industrial y habitacional, entre ciudad y naturaleza" (Lobos 2003: 44). También se mantiene el uso del concepto como una crítica hacia un modo de intervención estatal que invisibiliza modos de habitar distintos a un proyecto centralizado (FSP 2016).

Existen numerosos usos para al concepto en la literatura insular. Por ejemplo, se plantea como maritorio el espacio archipielágico en el que se congregaron las poblaciones canoeras impactadas traumáticamente por la llegada de conquistadores europeos (Cárdenas y GraceHall 1991). Ello asumiendo que para estas comunidades nómades el paisaje habitado y sentido no estaba separado entre tierra y mar, como sí era percibido por los colonizadores. Tamayo (2011) refuerza esto al definir el maritorio como "el territorio entre mar y bordemar que establecían las sociedades indígenas, siendo el espacio central de desarrollo cultural" (Tamayo 2011: 15).

Por otro lado, se aborda este concepto como reconocimiento hacia un modo de ser local que adquiere especial sentido para quienes portan y experimentan la cultura chilota (Chapanoff 2006, 2005 2003), lo que transforma el mar o la mar en un medio, un catalizador de la vida. Este concepto también se utiliza para dar sentido en Chiloé a la conjugación entre el mar, las apropiaciones socioculturales y los actores, en una construcción social de un tiempo particular: pasado, presente y futurizaciones (Ther 2011) que tiene expresiones materiales que cohabitan (Figura 3 y 4). Esta idea es reforzada por otros autores, siempre bajo la lógica de incluir a esta fusión y ensamblaje de mar/tierra el componente temporal, o reforzar la idea de un espacio constantemente transicional (Brintrup 2012; Gajardo 2015, 2014) pero que almacena una memoria reconocible inmaterial y materialmente: “(...) una biografía colectiva que ha depositado sobre sus costas una estratigrafía marcada por transformaciones humanas" (Álvarez y Ther 2016: 309). Incluso Cárdenas le otorga un carácter fungible "La comunidad es la memoria de este pueblo. Si el trabajo asalariado y su compleja filigrana ideológica se insertan en este pueblo, terminarán desintegrándolo. Al mismo tiempo, liquidarán sus territorios y maritorios, matrices biológicas de la vida" (Cárdenas 2016: 325). Esto último no debe entenderse sólo como 
un espacio afectado ambientalmente, sino como una cultura marítima ligada a la naturaleza del mar que desaparece junto a éste.

Figura 3. Dos tipos de embarcación chilota que dan cuenta de dos tiempos en el maritorio

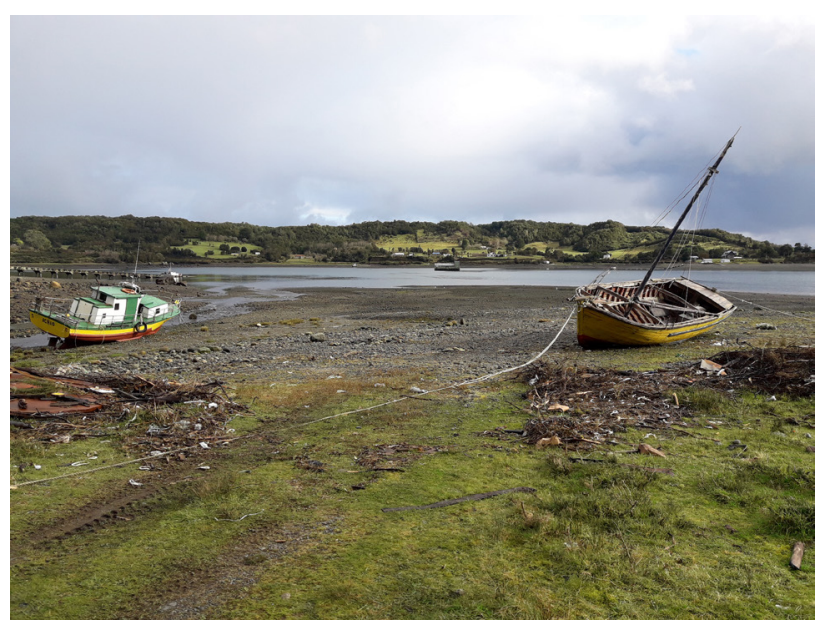

Fotografía: costa interior de Isla Butachauques, Comuna de Quemchi. Ricardo Álvarez 2016.

En tiempos recientes, en el Archipiélago de Chiloé y los Canales Australes -afectados por múltiples amenazas ${ }^{7}$ - el concepto de maritorio adquiere un sentido político-territorial estratégico, de vida y de soberanía para sus habitantes (Domenech 2003, Gajardo et al. 2016), siendo utilizado en herramientas de zonificación marina y propuestas de conservación (Hucke-Gaete et al. 2010; Luna 2009; Molina 2013; Torres 2017), o simplemente referido como un espacio reconocible en el que suceden siniestros

Eutrofización marina, proyectos mineros, externalidades negativas de la acuicultura, conflictos entre actores por superposición de usos no compatibles entre sí, etc.
Figura 4. Embarcación fabricada con la mitad de una boya de origen acuícola. El ingenio local hace que la basura flotante (externalidad negativa de esta industria) cobre vida útil

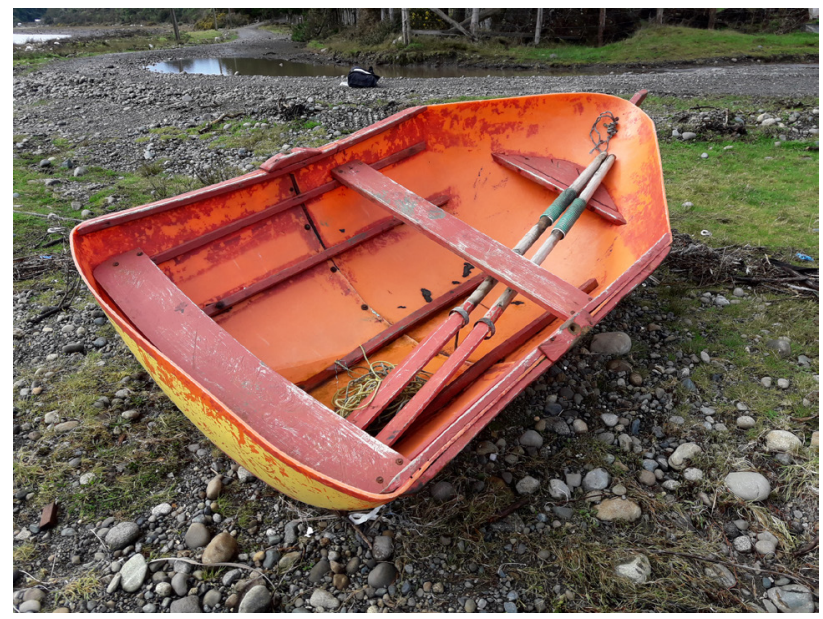

Fotografía: costa interior de Isla Butachauques, Comuna de Quemchi. Ricardo Álvarez 2016.

socioambientales (Contreras 2013) que afectan gravemente el modelo de vida campesinopescador de Chiloé. Se plantea, asímismo, como espacio en el que suceden fenómenos analizables y medibles (Hidalgo 2014). También se sugiere como término para complementar los estudios en arqueología marítima (Herrera y Chapanoff $2017^{8}$ ).

Aunque en este artículo se hace necesario discutir la autoría del concepto tal como lo plantean estos autores 


\section{Exoducción: El concepto de maritorio en un escenario internacional y de futuro}

De nueva cuenta, es interesante señalar que discusiones similares ocurren en otras latitudes, siendo muy pertinente al caso los estudios desarrollados por Hayward (2012) y otros autores $^{9}$ que están discutiendo hoy en día la forma de comprender y abordar contextos isleños del mundo, utilizando para ello términos como aquapelago: "An assemblage of the marine and land spaces of a group of islands and their adjacent waters" cuyas sociedades "(...) existing in a location in which the aquatic spaces between and around a group of islands are utilised and navigated in a manner that is fundamentally interconnected with and essential to the social group's habitation of land and their senses of identity and belonging" (Hayward 2012: 5). Por ello, hoy en día se abre un escenario pertinente para colaborar desde la experiencia austral, e incluir el concepto de maritorio en una discusión internacional que, con fuerza, subraya en la necesidad de mirar los tiempos modernos sin poner en riesgo las tradiciones y condiciones particulares de territorios específicos. Tradiciones y condiciones particulares que en el caso del maritorio de Chiloé son parte fundamental de lo que ha sido, es y puede llegar a ser. En esta línea, y basados en la noción de espacio vivido (Lefebvre, stricto sensu) hemos propuesto para el Archipiélago de Chiloé el constructo de Áreas Geoculturales Marítimo-Costeras $(A G C M)^{10}$, un recurso teórico-metodológico que entiende al maritorio según distintas intensidades de apropiaciones,

http://shimajournal.org/anthologies.php\#aquapelago

10 Proyecto FONDECYT 1121204 "Geoantropología de los imaginarios del Mar Interior de Chiloé: itinerarios de temporalidades y apropiaciones socioculturales marítimas" (Ther-Ríos, F.; Álvarez Abel, Rdo.; Muñoz, J.; Saavedra, G.). 2012 - 2016. usos y cotidianeidades pretéritas y actuales, y que futuriza su funcionamiento, basado en las interrelaciones de una gran matriz socioterritorial en funcionamiento (ver figura 5), y desde donde es absolutamente necesario promover acciones de desarrollo territorial diferenciado, concordantes con la concepción original de maritorio.

Figura 5. Áreas Geoculturales Marítimo-Costeras (AGCM).

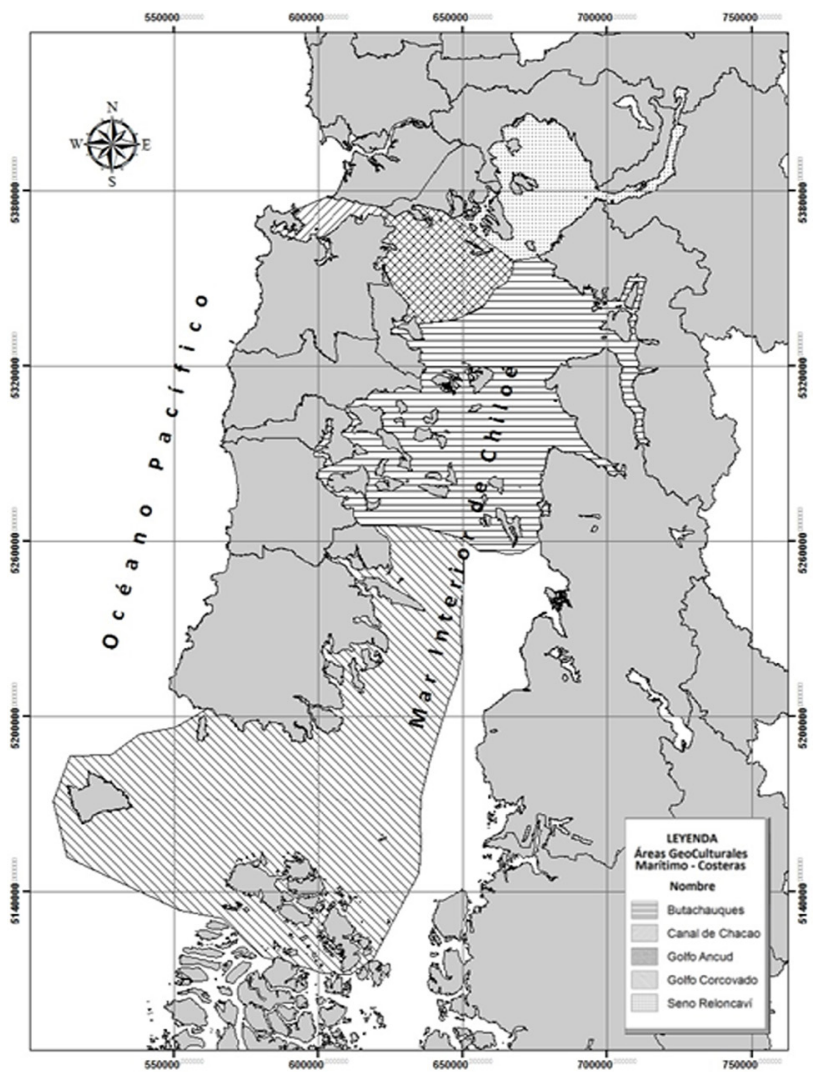

Fuente: Proyecto FONDECYT 1121204. 
Hoy en día existe una red de navegaciones insulares subvencionadas, acompañada de rutas terrestres, que se orientan bajo la lógica de acercamiento entre isleños que no pueden ser conectados vía puentes con el continente. Esta lógica es ad-hoc con el origen de este subsidio, ya que nació como compensación frente a la inversión realizada en el proyecto Transantiago ${ }^{11}$. El efecto que esto ha tenido en los y las isleñas es notorio. El tejido relacional que existía hasta hace poco tiempo (sustentado no sólo en recolectar recursos marino-costeros, sino también en festividades, intercambio, torneos de fútbol, velorios, etc.) se ha debilitado enormemente (Hidalgo et al 2015; FSP 2016). Sin embargo, los propios usuarios manifiestan estar contentos pues el bajo costo de este transporte alivia sus economías isleñas: hoy en día gran parte de estas familias -que antaño se movilizaban libremente- viajan unidireccionalmente hacia garitas situadas en carreteras asfaltadas para tomar minibuses que los llevan hacia ciudades, o directamente a éstas. Es "más eficiente", término sobreutilizado por el Estado para justificar sus intervenciones, y que poco a poco se incorpora al modo de pensar y ser en la insularidad, normalizándose como el propio modelo de desarrollo imperante. Con ello, el maritorio -y la cultura "portable" a través de la libertad de navegar autónomamente- se sitúa en un alto grado de vulnerabilidad que sólo se mantiene gracias a la movilidad de personas y objetos (Lazo y Ther 2014) que ocurre más bien en la invisibilidad, pues así no puede ser fiscalizada.

\footnotetext{
Transantiago es el transporte público de la ciudad de Santiago inaugurado el 2005 y cuyo subsidio adquirió tales proporciones que motivó a los legisladores regionales a presionar para que el Estado compensara en parte a sus distritos por el drenaje de recursos involucrados en ese proyecto. Los recursos así obtenidos se han destinado por ley a obras y mejoras en la conectividad asociada al transporte público en regiones.
}

El Archipiélago se transforma finalmente en un territorio en el que la conectividad eficiente del Estado instala carreteras sobre el mar, que son fielmente utilizadas por las embarcaciones subvencionadas. Las economías isleñas son muy robustas para asegurar el auto mantenimiento dentro de ellas, pero les cuesta mucho generar dinero, único medio para interactuar en las ciudades y acceder a sus "adelantos" y servicios. Por ello, cada vez que surge la posibilidad de utilizar una subvención los y las isleñas se acogen a éstas. Lo complejo del asunto es que no hubo otras alternativas de por medio: el mar está afecto de restricciones que impiden tomar decisiones libremente, y seriamente fragmentado debido a las concesiones acuícolas que operan bajo la lógica de propiedad privada obstruyendo la movilidad. La única salida que queda finalmente para estas familias es subirse a estas carreteras acuáticas, mientras el resto del mar es dejado a manos del extractivismo. Claramente, el deterioro de este tejido social insular facilitará aún más este proceso.

La avanzada progresiva de una racionalidad urbana, continental y terrestre sobre estos archipiélagos invita a repensar, a través del concepto de maritorio, las actuales políticas públicas y proyecto de desarrollo. También, a analizar cómo elementos que antes formaban parte integral del habitar se transforman en objetos disociados, y en el proceso sus habitantes se disocian de su insularidad. Incluso sus cohabitantes cobran un sentido siniestro, como sucede actualmente con los lobos marinos y otras especies marinas que son señaladas como una amenaza para las labores extractivas: hoy en día recurrentemente los pescadores artesanales y representantes de la industria salmonera señalan que la merma de recursos 
pesqueros, y de los peces que se crían en balsas jaulas, es causada por éstas, invisibilizando con ello sus propias responsabilidades. Este imaginario es transferido a los niños y niñas, quienes refuerzan esta idea de que habitar lo urbanizado y regulado es seguro (Figura 6).

Figura 6: llustración hecha por los estudiantes de la escuela rural de isla Autení, subgrupo Desertores, comuna de Chaitén, en la que un lobo marino cobra dimensiones dantescas frente a sus habitantes, devorando un pez que es su fuente de trabajo



Fotografía: Ricardo Alvarez 2017.

Como contra respuesta es necesario señalar que los y las isleñas siguen afirmando que el elemento más valioso (no monetarizable) de las islas es la tranquilidad. Con ello queda claro que están experimentando un proceso de reflexividad tensionado por lógicas que se confrontan constantemente. Su acercamiento hacia el proyecto de desarrollo impulsado por el Estado los considera como "beneficiarios", en un ejercicio que no les deja opción para decidir. Por ello, el maritorio -como argumento para promover la discusión entre múltiples actores- se presenta como un desafío para avanzar en la comprensión de los procesos territoriales donde se agotan las categorías taxonómicas tradicionales con las que han operado la Ciencia y administración pública. La separación radical de mar y tierra es un reflejo más de una construcción occidental del mundo, que es extraordinariamente funcional para los fines de una explotación extractivista gobernada centralizadamente. También encarna la artificiosa separación entre naturaleza y cultura y entre lo material e inmaterial. Por el contrario, el maritorio representa la fluidez, hibridez y yuxtaposición con que se dan los procesos socioambientales y socioculturales, donde se entiende a los seres humanos en su mutua dependencia con las demás especies. El maritorio es también una provocación frente a una concepción convenientemente instrumental del medio que busca - como aquí se sugiere - imponer un modo de vida que no hace sino servir los intereses económicos del mercado y que, como contraparte, acarrea consigo el desarraigo de las poblaciones locales y la destrucción de sus medios de vida.

No es de extrañar que el Archipiélago de Chiloé haya sido inspirador de una visión integradora. No en vano han sido el Mar Interior y sus rutas los que han permitido el despliegue de una cultura que no hace gran distingo entre habitación y embarcación. De modo anticipatorio, y desde un campo distante tanto en lo disciplinar como en lo geográfico, fue un grupo de arquitectos el que acuñó el concepto de maritorio, contribuyendo con ello a enriquecer el debate sobre nisología o estudio de las islas (v. gr. McCall 1994) desde la singularidad de habitar en y desde el mar. Es de justicia reconocerles su autoría. 


\section{Bibliografía}

Álvarez, R. y Ther, F. 2016. "Los tiempos del mar interior". Chiloé. Santiago de Chile: Museo de Arte Precolombino - Banco Santander. 312-323. Editor: Aldunate, C.

Álvarez, R. 2016. "Reflexiones en torno a la ubicación espacial de corrales de pesca en Chiloé insular y continental" (213-223). Arqueología de la Patagonia, de mar a mar. IX Jornada de arqueología de la Patagonia, 20 al 25 de octubre de 2014. Coyhaique: Ñire negro. 213-223.

Brintrup, G. 2012. "Pompa, ceremonia y rito en Chiloé". Arquitecturas del Sur 41: 6-15.

Escuela de arquitectura PUCV. 1971. "Maritorios de los Archipiélagos de la Patagonia Occidental. Fundamentos de la Escuela de Arquitectura. Universidad Católica de Valparaíso". Santiago de Chile: Talleres del Consejo de Rectores de las Universidades Chilenas. 19 páginas.

Cárdenas, R. 2016. "Chiloé en el ojo del volcán”. Chiloé. Santiago de Chile: Museo de Arte Precolombino - Banco Santander. 325-328. Editor: Aldunate, C.

Cárdenas, R. y Grace-Hall, C. 1991. Chiloé: manual del pensamiento mágico. Santiago de Chile: Imprenta Olimpho.

Chapanoff, M. 2006. La Invención del No Lugar: El Maritorio en la Noción de los Navegantes del Archipiélago de Chiloe. Ponencia presentada en el simposio: Etnografías del Siglo XXI, en el Cuarto Congreso Chileno de Antropología. 19 al 23 de Noviembre de 2001, Santiago de Chile.

2005. "Imaginario y maritorio: relatos, fábulas y mitos del mar". Chile, País Oceánico. Santiago de Chile: Ocho Libros Editores. 37-53 Editor: Gonzalo Badal.

2003. "El mundo invisible: identidad y maritorio". Revisitando Chile: Identidades, Mitos e Historias. Montecinos, S. (ed.). Santiago de Chile: Cuadernos Bicentenario, Presidencia de la República. 240-246.

Contreras, V. 2013. "El gorro de lana: una relectura de Chiloé a través de una popular canción de los años 70". Insularidad e imaginario intercultural Canarias-Chiloé (ecos de un encuentro). Suárez, Z. y Rodríguez, O. (ed.). Santiago de Chile: Ediciones Lar. 15-30.

Domenech, R. 2003. Posicionamiento comunitario del maritorio y la intervención en el desarrollo rural: El caso de la comunidad huilliche de la Isla Caylin. Tesis para optar al grado de licenciatura en antropología. Valdivia: Universidad Austral de Chile.

Fundación Superación Pobreza (FSP) 2016. Crisis en el habitar insular: representaciones, significados y sentimientos de los habitantes del mar interior de Chiloé sobre la crisis sociocultural y productiva de la isla, sus dinámicas presentes e imágenes del futuro. Osorno: Estudio regional Los Lagos.

Gajardo, P., Mondaca, E. y Santibáñez, P. 2016. La minería industrial como una nueva amenaza al espacio marino costero de Chiloé: Bahía de Cucao como caso de estudio. Santiago de Chile: Centro de Estudios Sociales de Chiloé.
Gajardo, P. 2015. "Construcción de género en la ruralidad insular de Isla Alao". Iberoamérica Social. Revista, Red de estudios sociales IV: 175-184.

2014. Isla Alao: Ruralidad insular y procesos de modernización. Tesis para optar al grado de Magíster en Antropología. Santiago de Chile: Universidad Academia de Humanismo Cristiano, Chile.

Guerra, D. 2013. "La Ruralidad Chilena Actual. Aproximaciones desde la Antropología editado por Roberto Hernández Aracena y Luis Pezo Orellana". Chungara 45(3): 497-499.

Gupta, A. y Ferguson, J. 1997. Culture, power, place: Explorations in critical anthropology. Durham: Duke University Press.

Hayward, P. 2012. "Aquapelagos and aquapelagic assemblages". Shima: The International Journal of Research into Island Cultures, 6(1): 1-11.

Herrera, J. y Chapanoff, M. 2017. "Regional Maritime Contexts and the Maritorium: A Latin American Perspective on Archaeological Land and Sea Integration". Journal of maritime archaeology 12(3): 163-178.

Hidalgo, C. 2014. Paisajes de la complejidad marítimocostera: actores, dinámicas y escenarios territoriales en la comuna de Quinchao, isla grande de Chiloé. Tesis de Magíster Universidad de Los Lagos, Chile.

Hidalgo, C., Ther, F., Saavedra, G., y Díaz, A. 2015. "Affordance of landscapes and economic socio-spatial networks in the Quinchao archipelago, Chile: a contribution to landscape research and island studies". Island Studies Journal, 10(1): 49-70.

Hucke-Gaete, R., Lo Moro, P., Ruiz, J. (eds.). 2010. Conservando el mar de Chiloé, Palena y Las Guaitecas. Vadivia: Imprenta America.

Ivelic, B. y Segura, E. 2016. "Recuperar nuestro destino marítimo en la concepción de un maritorio habitable y sustentable". Revista AUS 19: 88-93.

Ivelic, B. 2005. Embarcación Amereida y la épica de fundar el mar en Patagonia. Valparaíso: Escuela de arquitectura y diseño, Escuela de arquitectura de Valparaíso.

Kolasa, J. y Zalewski, M. 1995. "Notes on ecotone attributes and functions". Hydrobiologia 303: 1-7.

Lazo, A. y Ther-Ríos, F. 2014. "L'univers du voyage géographie matérielle et sensorielle des mobilités dans l'Archipel de Chiloé, Chili”. Géographie et cultures 91-92: 49 -64.

Lobos, J. 2003. "Concurso en Barakaldo". ARQ (Santiago) 55: 44-47.

Luna, F. 2009. A pura memoria: conocimientos y significados de la naturaleza en las localidades de Melinka y Repollal, litoral norte de la región de Aysén. Tesis para optar al grado de antropóloga. Valdivia: Universidad Austral de Chile.

McCall, G. 1994. "Nissology: The study of islands". Journal of the Pacific Society 17(2-3): 1-14. 
Molina, C. 2013. "Hacia paisajes banales: estudio sobre normativas e imaginarios en la ciudad de Castro, Isla de Chiloé, región de Los Lagos, Chile". Espacio Regional, 2(10): 51-74.

Scott, J.C. 1998. Seeing Like a State: How Certain Schemes to Improve the Human Condition Have Failed. New Haven: Yale University Press.

Skewes, J.C., Alvarez, R. y Navarro, M. 2012 (a). "Usos consuetudinarios, conflictos actuales y posibilidades de conservación en el borde costero de Chiloé insular". Revista Magallania 40(1):107-123.

Skewes, J., Solari, M., Guerra, D., y Jalabert, D. 2012 (b). "Los paisajes del agua: Naturaleza e identidad en la cuenca del río Valdivia". Chungará 44(2): 299-312).

Tamayo, M. 2011. Las vetas de un saber mestizo. Maestros de ribera de Hualaihué. Valdivia: Ed. Kultrún.

Ther, F. 2011. "Configuraciones del tiempo en el mar interior de Chiloé y su relación con la apropiación de los territorios marítimos". Desenvolvimento e Meio Ambiente 23: 67-80.

Torres, V. 2017. Respuestas locales frente a la dinámica laboral propiciada por la industria salmonera en la localidad rural de Pureo, Chiloé. Tesis Antropología Universidad Academia de Humanismo Cristiano, Chile. 